\section{Journal of Applied Research and Technology}

www.jart.icat.unam.mx

Journal of Applied Research and Technology 17 (2019) I63-I7I

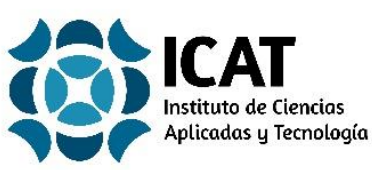

Original

\title{
Devolatilization of a particle coal in a plasma reactor
}

\author{
Juan Diaz-Gomez ${ }^{*}$, Joel Pacheco-Sotelo, Ricardo Valdivia-Barrientos \\ Marquidia Pacheco-Pacheco
}

Departamento de Estudios del Ambiente

Instituto Nacional de Investigaciones Nucleares

Carr. Mexico-Toluca, Ocoyoacac, México.

\begin{abstract}
In this paper, a warm plasma reactor is used to increase the discharge by the addition of 3 different nitrogen-coal carbon mixtures. An experimental study was carried out to determine the temperatures profile in a jet plasma along the chamber, according to nitrogen/coal ratio and power consumption. The coal particle was also characterized in function of its size. An important effect when the volatile components released from the coal is manifested and passing through the plasma jet, this produce the plasma jet increase. This effect has a great importance to performance improvement in plasma reactor profitable for greenhouse gas (GHG) treatment. As a consequence, the high temperature surrounding the plasma jet, augments the degradation capacity.

The experimental analysis, the kinetic parameters of the combustion of nitrogen-coal mixture was taking in consideration, as well as the appearance of a considerable amount of new radicals. In addition, increasing the plasma jet has a significant impact on the overall reactor performance of coal particles that release volatile component. This allows prompt increase and much enhanced plasma jet stability.

The aim of this study was to evaluate and develop a model in order to know the temperature behavior in a plasma jet. Different sizes of coal particles at specific rate of $5 \mathrm{slm}$ (standard liter per minute) of a nitrogen-coal mixture have been simulated in this model. The advantages of this technique is to simulate other sizes of particle and obtaining the best condition and operating parameters of plasma reactor.
\end{abstract}

Keywords: coal particles, simulation, warm plasma

\section{INTRODUCTION}

Coal is the main energy input in many industries. In the power plants it is utilized as a fuel source (Smoot, \& Smith, 2013; Pacheco et al., 2014). An important progress in gasification technology came with the

${ }^{*}$ Corresponding author.

E-mail address: Juan.diaz@uaem.mx (Juan A. Diaz)

Peer Review under the responsibility of Universidad Nacional Autónoma de México. introduction of plasma torches in the process to contribute the reduction of GHG emissions (Burguete et al., 2016; Gai, Guo, Liu, Peng, \& Liu, 2016; Matveev, Ardelyan, Bychkov, Bychkov, \& Kosmachevskii, 2013). 


\subsection{CHANGE OF CHEMICAL COMPOSITION PROCESS IN A PLASMA TORCH.}

Coal reaction process starts with the extraction of volatile components contained in coal particles. Then the coal particles are heated, so they progressively emit the volatile component to the surroundings and its reaction occurs when the temperature becomes high enough for the mixture of the volatile component and gas. Once reaction starts, flame accelerates the release of the volatile component of the coal particles; as a consequence, the particles are heated quickly.

Coal volatilization is acknowledged as the first step and also of primary importance in coal thermal conversion techniques, such as coal coking, gasification, combustion (Askarova, Karpenko, Lavrishcheva, Messerle, \& Ustimenko, 2007).

In reference Sugimoto et al. (2002), the experimental configuration, injecting three different powders as an igniter and stabilization plasma torch was developed. They found when the powder has a more volatile matter in its composition a greater combustion in the plasma succeeds. The pulverized coal combustion experiment with plasma shows that it can be ignited with only $10 \%$ of the total power.

In 2014, Yan, Cao, Cheng, Jin, \& Cheng (2014) presented the effects of coal properties, particle ultimate temperature and heating rate were also found, in order to predict pyrolysis behaviors at high temperatures with different heating's rates.

The employed of different environments in the devolatilization processes have been studied in (Timothy, Sarofim, \& Béer, 1982). In general, Lemaire, Menage, Menanteau, \& Harion (2014) shown that an increase of the $\mathrm{O}_{2}$ percentage in the carrier gas leads to an increase of the apparent devolatilization rates as well as devolatilization decreases for the same quantity of $\mathrm{O}_{2}$ in the medium when using $\mathrm{CO}_{2}$ instead of $\mathrm{N}_{2}$ as a diluent.

Other study was developed to understand plasmaassisted ignition mechanisms on dispersed coal particles that may be applied in practical combustion system (Zhao, Li, Ren, Yao, \& Yuan, 2016). They founded that the plasma-assisted reduction of ignition delay time ranges from 2.9 down to $1.2 \mathrm{~ms}$, when ambient temperature increases from 1200 to $1800 \mathrm{~K}$ respectively.

Several studies investigating about the different coal particle ignition and operating conditions have been carried out on plasmas systems (Gorokhovski, et al., 2007; Singleton et al., 2011).

The volatile matter, consisting of all constituents coming from the decomposition of organic materials in coal, is an important index in the analysis of coal (e.g. moisture, volatile matter, fixed carbon and ash). In this work we analyzed the compositions of coal to ensure a better understandings of the role of the particle size of coal.

\subsection{DEVOLATILIZATION PHENOMENAL PHYSICS}

In the phenomenon of devolatilization is important to know the behavior of the coal particles inside the plasma. In reference work Tomeczek \& Kowol (1991) a number of investigations about the temperature profile in the coal particle and surface were carried out. In their tests, the temperature was measured with different particle sizes (diameters of $0.5-15 \mathrm{~mm}$ ), also they found the main resistance to generated volatiles were two: the heat conduction and mass transfer resistance.

On the other hand, authors (Messerle, Karpenko, Ustimenko, \& Lavrichshev, 2013; Messerle, Ustimenko, Askarova, \& Nagibin, 2010; Sijer, Belosevic, \& Stefanovi, 2005), they have developed models for the improve the environmental characteristics of the combustion of fuels. These models allowed investigating the complex processes of coal combustion and increases efficiency on its processes.

There are also other studies, which simulate the effect of the particle velocity and residence time into the plasma. In (Yan, Cheng, Jin, \& Guo, 2012) they investigated the effects of different designs to improve the coal particle devolatilization.

The aim of this study was to evaluate and validate the behavior of coal powders in a warm plasma torch, the use of other sources of coal such as activated carbon, printer toner and ignition coal were also tested. This combustible mixture is easily decomposing in milliseconds. This allows prompt increase and much flame stability enhanced in the main portion of the coal flame.

\section{EXPERIMENTAL}

The stainless steel plasma reactor has a capacity of 1 $\mathrm{kW}$. It is built with a double stainless steel wall, and has 
a recirculation cooling system: the purpose is to keep the reactor at low temperature, when there is reaction of the coal powders occurs. A Nitrogen plasma gas is introduced at a rate of $15 \mathrm{slm}$ (standard liter per minute), for plasma formation. Nitrogen acts as a neutral gas and mainly to maintain the discharge. Fig. 1, shows the reactor setup with its different process components.

The discharge is generated between two electrodes (tungsten-steel) under specific conditions of flow and power. Feeding a torch with a powder is a delicate operation if one aims to control correctly the flow of particles and the homogeneity of the mixture of particles and gas, that is why the coal powders are first introduced in the coal powder chamber. A flow of nitrogen is applied at a rate of $5 \mathrm{slm}$, in order to gas drag the powders through the pipe, until reaching the chamber where the plasma arc is generated. The chamber where the change of chemical composition of the powders was carried out has an inner diameter of 6 $\mathrm{mm}$.

In order to analyze the chemical species as a result the coal reaction in the plasma, the exhaust gases, pass through a pipe, which is used to take a representative sample. Then they, subsequently pass to a Gas
Chromatograph and a Gas Analyzer, where the components and the resulting concentrations of the exhaust gases are analyzed. At the same time the plasma was analyzed by optical spectroscopy: this measurement is performed when the plasma is formed and immediately after mixture of nitrogen and coal was added in order to observe the species involved, and determine the temperature in the plasma jet after the interaction of the coal powders. For more details of the experimental setup are shown in previous work (Pacheco et al., 2014).

In the experimental part, we have tested 3 different particle sizes of coal powder: $4 \mu m$ (print toner), $10 \mu m$ (ignition powder), activated carbon $(20 \mu \mathrm{m})$, in order to observe the behavior of the plasma in the stream. Table 1 summery the entire developed test.

Table 1. Different test developed in the plasma reactor for coal powder.

\begin{tabular}{lll}
\hline $\begin{array}{l}\text { Material } \\
\text { Coal } \\
\text { powders }\end{array}$ & $\mathbf{N}_{2}(l / \mathrm{min})$ & Coal $(\mathrm{g} / \mathrm{min})$ \\
\hline Test $\mathbf{1}$ & 5 & 5 \\
Test 2 & 5 & 10 \\
Test 3 & 5 & 15 \\
\hline
\end{tabular}

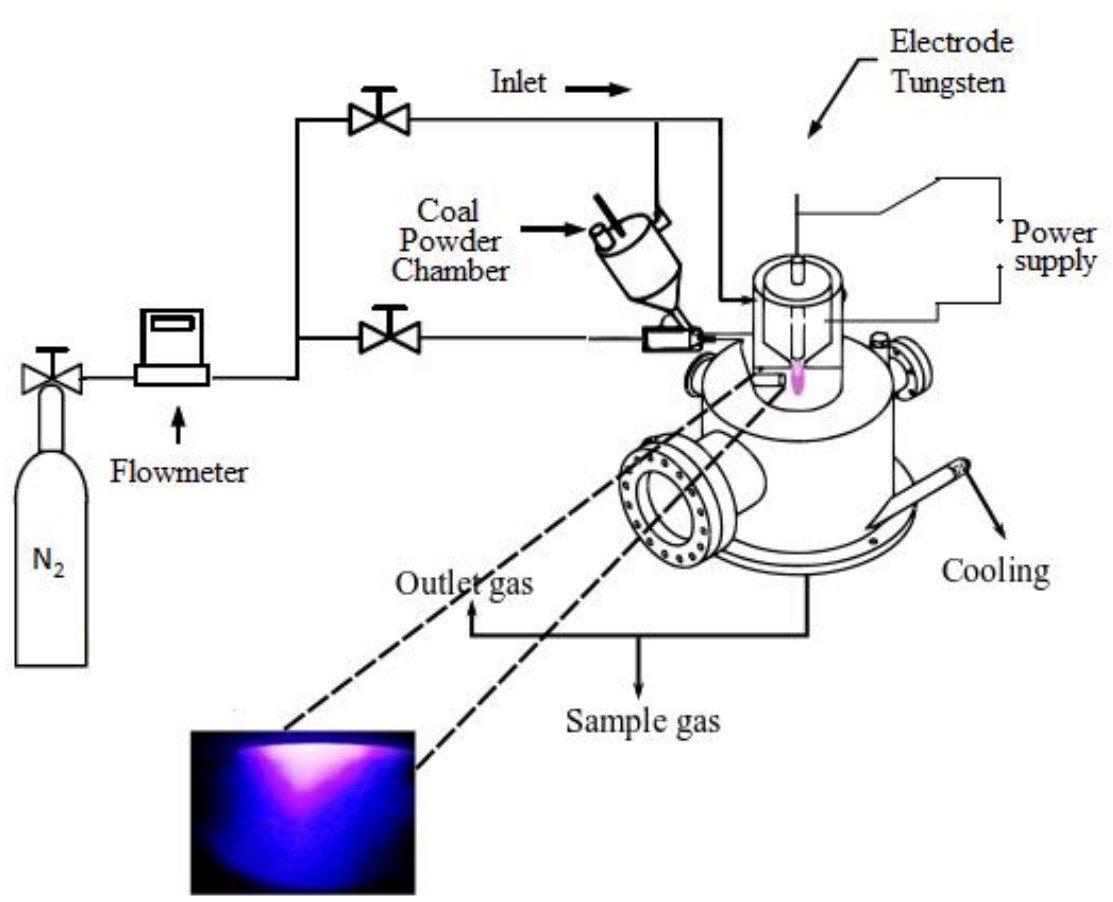

Fig. 1. Experimental setup. 


\section{RESULTS AND DISCUSSIONS}

\subsection{POWDER ANALYSIS}

During devolatilization, the evolution of the texture of the particles has been studied by measurement of their microporous surface area. The carbon sample sizes have been characterized in order to observe the particle size and composition of each sample. A JSM-610 scanning electron microscope (SEM) has been used for this purpose.

Fig. 2 shows a SEM image for the coal toner sample. It is observed that the average particle size is uniform around 4 and $5 \mu \mathrm{m}$. The particle size of coal toner is more regular than the other two coal powder (coal ignition, activated carbon).

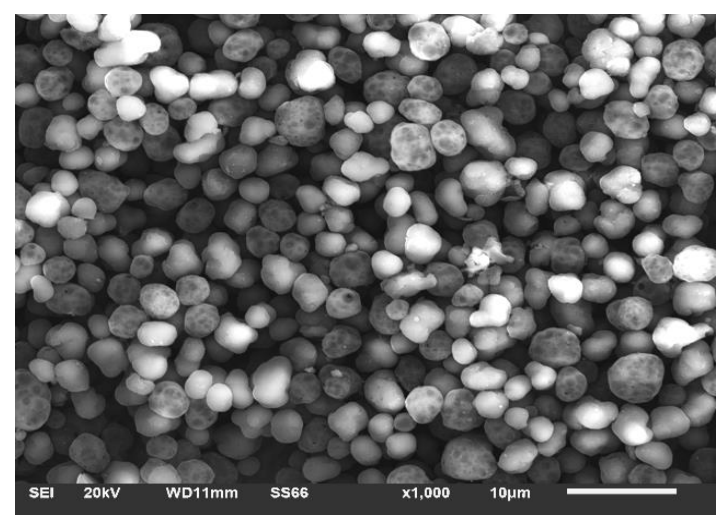

Fig. 2. Coal powder sample, SEM view for coal toner.

Fig. 3. shows the particle size of the ignition powder. In the image it is seen that the particle size is not uniform and there are different particle sizes, in our case a particle average of $10 \mu \mathrm{m}$ has been considered.

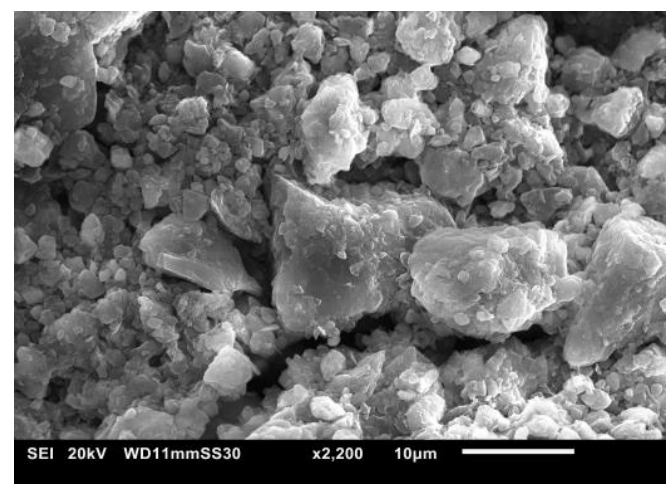

Fig. 3. Coal powder sample, SEM view for coal ignition.
Also the image of last sample, the activated carbon (average size $20 \mu m$ ) is shown in Fig 4.

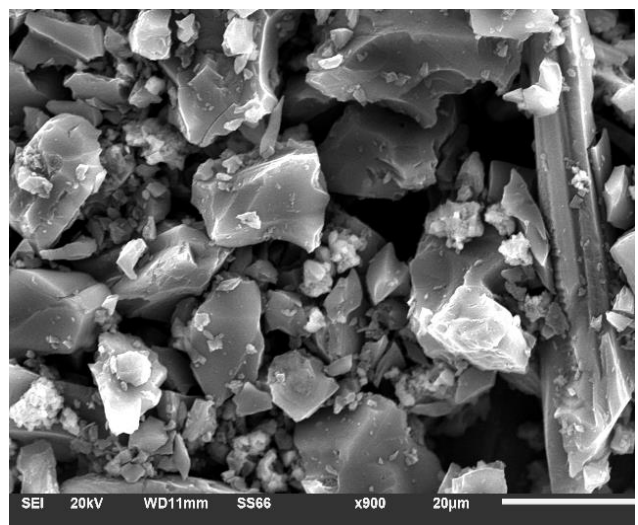

Fig. 4. Coal powder sample, SEM view for Activated carbon.

The obtained characteristics of chemical composition for the three coal powders are shown in the Table 2.

Table 2. Chemical composition of coal powders, mass \%.

\begin{tabular}{llll}
\hline Characteristics & $\begin{array}{l}\text { Printer } \\
\text { toner }\end{array}$ & $\begin{array}{l}\text { Coal } \\
\text { ignition }\end{array}$ & $\begin{array}{l}\text { Activated } \\
\text { carbon }\end{array}$ \\
\hline Mean size & $4 \mu \mathrm{m}$ & $10 \mu \mathrm{m}$ & $20 \mu \mathrm{m}$ \\
\hline Elemental composition & & & \\
C (\% mass) & 86.98 & 54.73 & 76.17 \\
O (\% mass) & 11.75 & 33.84 & 16.94 \\
Si (\% mass) & 1.27 & 11.43 & -- \\
P (\% mass) & -- & -- & 2.15 \\
Ca (\% mass) & -- & -- & 4.74 \\
Volatile matter & 61 & 22 & 30 \\
(wt\%, dry basis) & & & \\
Fixed carbon & 29 & 67 & 48.9 \\
(wt\%, dry basis) & & & \\
Ash (wt\%, dry basis) & 10 & 11 & 21.1 \\
& & & \\
\hline
\end{tabular}

A thermo-gravimetric analysis was used to measure the volatile content of the three carbon samples. The matter volatile content was compared with the thermodynamic approximation obtained in the part of model considerations. The analyzer used was (TGA / DSC 1), in which it was set at a rate of $20^{\circ} \mathrm{C} / \mathrm{min}$ until reaching $1000{ }^{\circ} \mathrm{C}$. The carbon samples analyzed were $5 \mathrm{mg}$. Fig. 5 . shows the Mass fraction (\%) behavior of the 3 carbon samples used, with respect to temperature. 


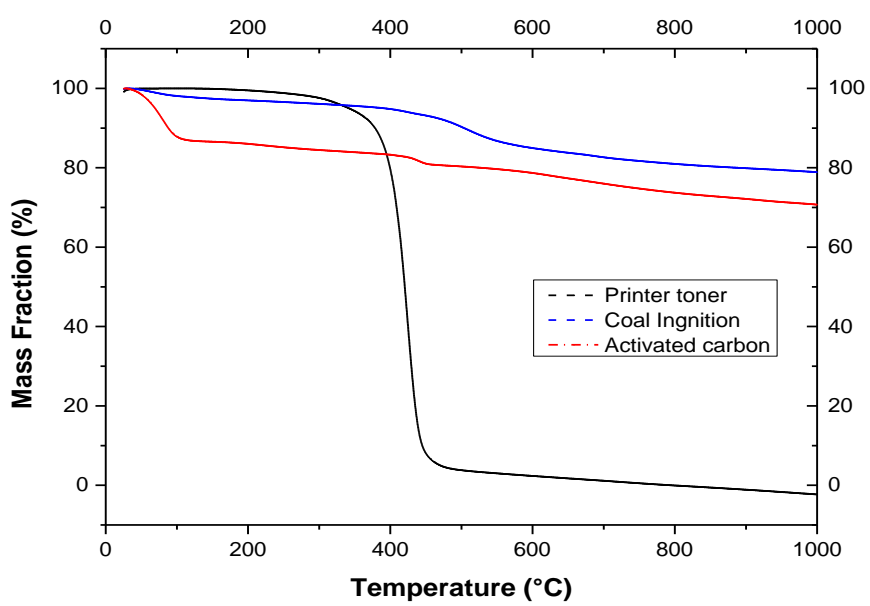

Fig. 5. Variation between temperature and mass fraction of the three samples during the heating.

The mass of samples are normalized by the initial value.

\subsection{MODEL CONSIDERATIONS}

In the work reported here we have developed a numerical model for the decomposition of pulverized coal particles in a two dimensional turbulent axisymmetric flow of nitrogen. The gaseous phase. One described within the Eurelian and lagrangian representation.

The flow of the gaseous phase (it's during the process of devolatilization) is considered in Eurelian field, for the general variable $\Phi$ (mass, momentum, energy, gaseous components), it gives as:

$\frac{\partial}{\partial x}(\beta u \Phi)+\frac{1}{r} \frac{\partial}{\partial r}(r \beta v \Phi)-\frac{\partial}{\partial x}\left(\Gamma_{\Phi} \frac{\partial \Phi}{\partial x}\right) \ldots$

$-\frac{1}{r} \frac{\partial}{\partial r}\left(r \Gamma_{\Phi} \frac{\partial \Phi}{\partial r}\right)=S_{\phi}+S_{P \Phi}$

Where $\Gamma_{\Phi}$ is transport coefficient of variable $\Phi$. $S_{\phi}$ and $S_{P \Phi}$ are resource terms from gaseous and particles phase. The $\beta$ is mixture density. All expression are found in (Belosevic, Sijercic, \& Stefanovic, 2008; Chen, Liu, \& Xia, 2009).

In recently years, many authors have included in their models the sequential and parallel reaction for improve the accuracy of the devolatilization process. In other cases they are used a semi-parallel reaction model, allows an estimation of the oxidation rate of the char, including the effect of devolatilization (Akaotsu et al., 2017; Howard \& Essenhigh, 1967). On this case the interaction between devolatilization and char oxidation is ignored, because in this processes the $\mathrm{N}_{2}$ gas was employed.

Since pyrolysis of a single species typically can be described as a simple first-order irreversible reaction, the rate of contribution to devolatilization by a particular reaction within the coal structure is given in the form (2).

$\frac{d V}{d t}=k_{v}\left(V^{*}-V\right)$

$V^{*}$ and $V$ indicate the total volatile matter content in the coal $(\mathrm{kg})$ and volatile mass released from the coal $(\mathrm{kg})$.

Here, ${ }^{k} v$ is given by the Arrhenius equation where:

$k_{v}=A_{v} \exp \left(\frac{-E_{v}}{R \cdot T_{p}}\right)$

$E_{v}$ is the activation energy $k J \cdot m^{-1}, R$ is the ideal gas constant and $T_{p}$ is particle temperature and $A_{v}$ is pre-exponential factor $\mathrm{s}^{-1}$. The values of $E_{v}$ and $A_{v}$ depend on the heating conditions and the temperature reached by coal particles, it is well known that a coal particle swells under the devolatilization process because its internal pressure and its viscosity increases. ( $\mathrm{Yu}$, Lucas, \& Wall, 2007).

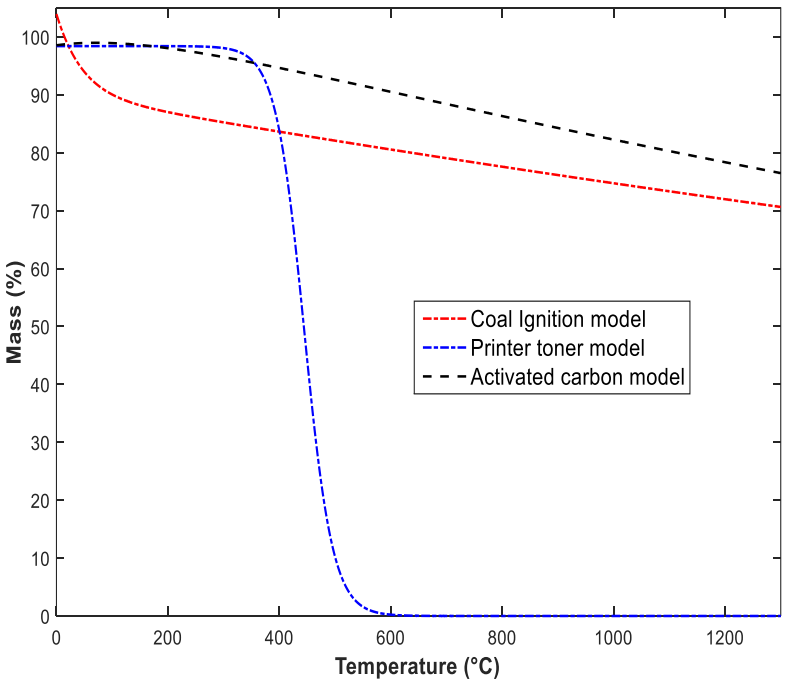

Fig. 6. Models of matter devolatilized of 3 coal powders. 
Once the behavior of the volatile component as temperature increases has been obtained (fig. 6), a simplified model has been obtained that describes the behavior of each kind of coal, it has been found that the equation that describes this behavior has the exponential form as follows:

$f(x)=\frac{A}{1+B \cdot e^{C \cdot x}}$

The following table 3 summarizes the values of the coefficients for each carbon powder obtained. The $x$ value in (4), represents the activation energy.

Table 3. values for each coefficient A, B, C.

\begin{tabular}{llllll}
\hline Coal & A & B & C & $\begin{array}{c}E_{v} \\
\left(J \cdot m o l^{-1}\right)\end{array}$ & $\mathbf{R}^{2}$ \\
\hline $\begin{array}{l}\text { Printer } \\
\text { toner }\end{array}$ & 99.3 & $1.29 \times 10^{-8}$ & 0.0433 & 8.35 & 0.995 \\
\hline $\begin{array}{l}\text { Coal } \\
\text { Ignition }\end{array}$ & 145 & 0.422 & $7.43 \times 10^{-4}$ & 16 & 0.955 \\
\hline $\begin{array}{l}\text { Activated } \\
\text { carbon }\end{array}$ & 24.13 & -0.7408 & $-1.82 \times 10^{-4}$ & 14.8 & 0.980 \\
& & & & & \\
\hline
\end{tabular}

In this case the particles are considered spherical and the Nusselt is equal to 2. The temperature of the boundary layer surrounding the particle was taken as the arithmetic mean of the temperature of the particle and of the surrounding gases (Serbin \& Matveev, 2010; Therssen, Gourichon, \& Delfosse, 1995).

$$
\frac{d T_{p}}{d t}=\frac{S_{p}}{m_{p} C_{p}}\left[\frac{N_{u} \lambda}{d_{p}}\left(\bar{T}_{g}-T_{p}\right)+\sigma \varepsilon\left(T_{p}^{4}-T_{0}^{4}\right)\right]
$$

Where $m_{p}$ is the particle mass and $C_{p}=943.298 \cdot \ln \left(0.01 \cdot T_{p}\right), \lambda$ is thermal conductivity of the gas by Eucken. Fig. 7, shows the temperature vs the residence time, the resulting is the behavior of the three coal powders in the reactor plasma. The carbon activated reach $1160{ }^{\circ} \mathrm{C}$ of temperature than the other two coal powders.

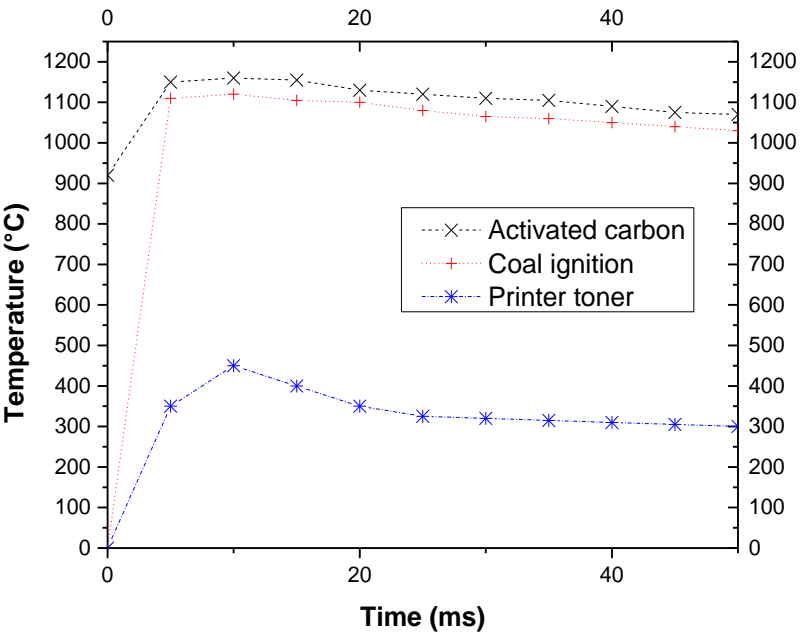

Fig. 7. Residence time in the reactor.

Additionally, the coal particles with a $20 \mu \mathrm{m}$ of diameter were injected from different positions to be submitted to different heating manner, obtaining performance differences during devolatilization. An analysis of the velocity profiles is performed as a radial distance function of the reactor. Fig. 8 shows the velocity profile in the plasma, when $\mathrm{N}_{2}$ is used as plasma gas at different temperatures as a radius function.

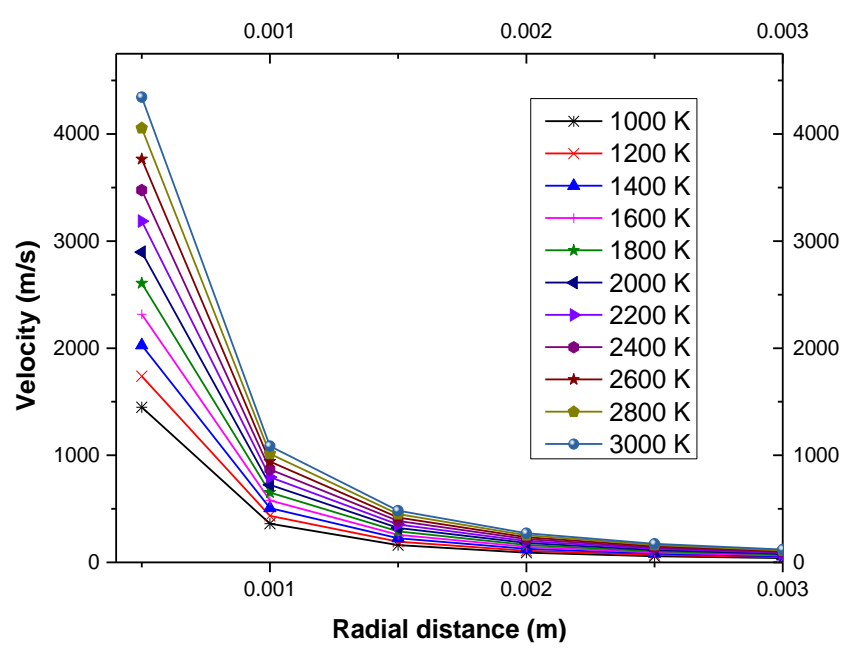

Fig. 8. Radial profiles of velocity of the plasma jet at different temperatures.

The images obtained in the experimental part are shown in Fig. 9, where $5 \mathrm{slm}$ gas plasma was used together with coal powders. First we observed only gas plasma $\mathrm{N}_{2}$, which has a characteristic color and low growth plasma. After coal powders are injected the growth of the plasma jet and the temperature increase. 
The dominant chemical species from the plasma were identified by using optical emission spectroscopy, showing atomic hydrogens $\left(H_{\alpha}, H_{\beta}\right.$, and $\left.H_{\gamma}\right)$, atomic nitrogen $(\mathrm{N})$, and oxygen $(\mathrm{O})$. In general, the gas temperature of plasma can be obtained from a rotational temperature of $\mathrm{N}$. The plasma showed temperatures of 6500 and $2000 \mathrm{~K}$ with an applied power of $1 \mathrm{~kW}$.

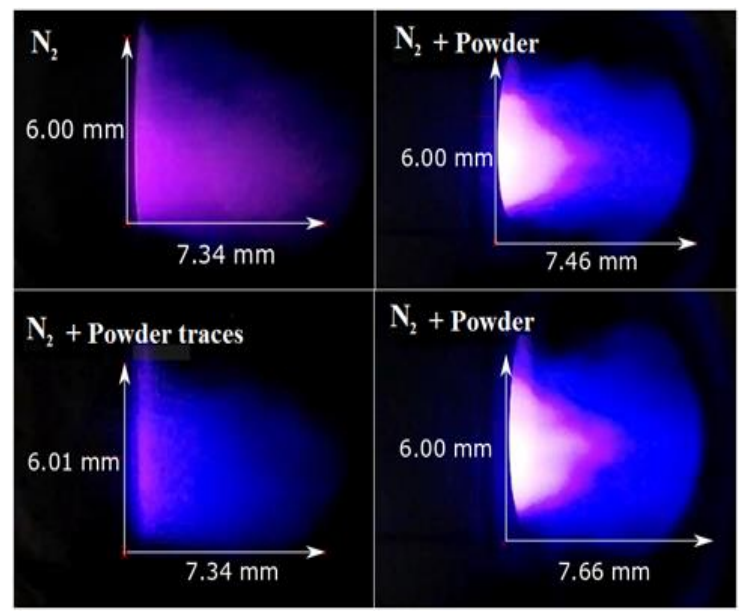

Fig. 9. Coal particle with nitrogen gas.

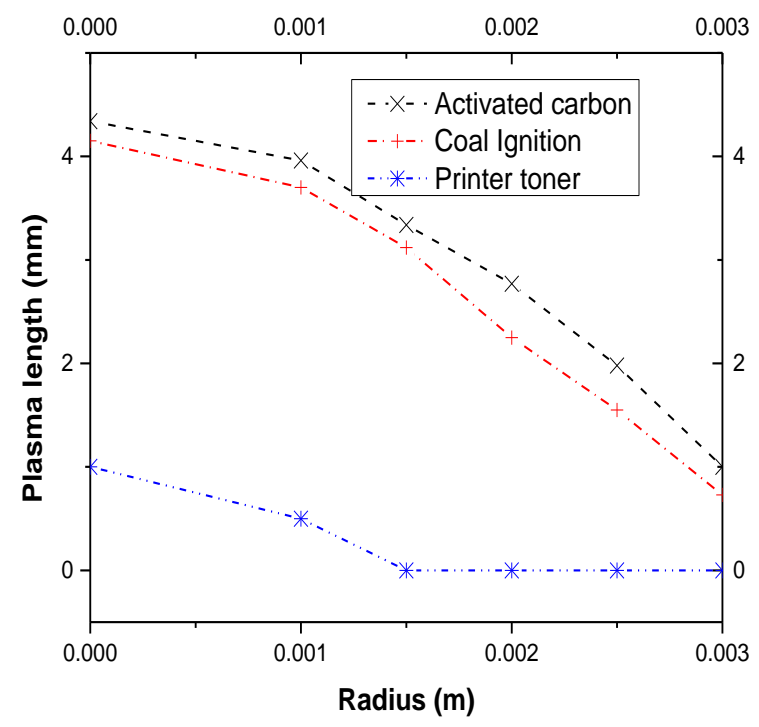

Fig. 10. Variation of plasma length with three coal powder.

The advantages in this process was the oxygen has not been employed and such case the coal powders do not ignite, the reaction of coal particles in the plasma it was enough and allows prompt increase and much enhanced plasma jet stability. This results in a more stable discharge, and an increase in the length of the plasma jet when it was used activated carbon and coal ignition. Fig. 10 shows the behavior of the plasma jet, when the three different carbon powders are injected, under the same powers and rates nitrogen gas.

\section{CONCLUSION}

The plasma jet appears to be a convenient technique for studying devolatilization of coal powders. Three coals have been tested and their devolatilization evaluated, mainly by monitoring the elemental composition of the chars obtained, through proximate analysis.

Overall, devolatilization rate constants, as well as activation energy $\left(E_{v}\right)$ (Printer toner: $8.35 \mathrm{~J} \cdot \mathrm{mot}^{-1}$, coal ignition: $16 \mathrm{~J} \cdot \mathrm{mot}^{-1}$, and activated carbon $14.8 \mathrm{~J} \cdot \mathrm{mot}^{-1}$ ) are obtained.

In the case of printer toner, $8.35 \mathrm{~J} \cdot \mathrm{mot}^{-1}$ was enough for free volatile matter, which is due mainly to the particle size and reactions with nitrogen gas. Both coal ignition and activated carbon have the activation energy very close values.

Also the mean size particle has been observed as well as the effect it has in the residence time in the plasma jet. It was found that for low size particles (Printer toner 4 $\mu \mathrm{m}$ ) the residence time at $10 \mathrm{~ms}$ reaches the maximum of $450{ }^{\circ} \mathrm{C}$, after decrease $150{ }^{\circ} \mathrm{C}$ and is hold on until free all volatile matter content.

The characteristics of the particulate matter are affected by the gaseous temperature. Also, they are affected by the pressure and the coal properties.

The devolatilization model is valid for the prediction of the characteristics of the particulate matter in the Nitrogen gas. The simplified model is obtained for each coal powders with the mean square error above 0.95 . This models are simplified for data extraction and easy access.

The experimental results obtained are in general agreement with the numerical results. Also, the length observed of the plasma jet increase (according to the fig. 10) with the addition of coal powders and therefore the discharge remains stable.

Onto the three coal powders analyzed, only the activated carbon and coal ignition powders show a stable and a larger increase in plasma length. Although the Printer toner powders contain enough volatile matter, the size is too small for a stable maintained at high temperatures in the plasma. 


\section{ACKNOWLEDGMENT}

The authors would like to thank for the invaluable support of the LAP laboratory of the ININ. Acknowledgments To: M. Duran, M. Hidalgo, F. Ramos; E. for technical support in the experiments. This work was developed under the support of CONACyT-SENER energy sustainability, project 234737.

\section{REFERENCES}

Akaotsu, S., Tanimoto, J., Soma, T., Saito, Y., Matsushita, Y., Aoki, H., \& Murao, A. (2017). Development of semiparallel reaction model of devolatilization and heterogeneous reaction for pulverized coal particles.

Fuel-ProcessingTechnology, 158, 104-114. https://doi.org/10.1016/j.fuproc.2016.12.011

Askarova, A. S., Karpenko, E. I., Lavrishcheva, Y. I., Messerle, V. E., \& Ustimenko, A. B. (2007). Plasma-supported coal combustion in boiler furnace. IEEE Transactions on PlasmaScience,35(6-PART 1), 16071616.

https://doi.org/10.1109/TPS.2007.910142

Belosevic, S., Sijercic, M., \& Stefanovic, P. (2008). A numerical study of pulverized coal ignition by means of plasma torches in air-coal dust mixture ducts of utility boiler furnaces. International Journal of Heat and Mass Transfer, 51 (7-8), 1970-1978.

https://doi.org/10.1016/j.ijheatmasstransfer.2007.06.003

Burguete, P., Corma, A., Hitzl, M., Modrego, R., Ponce, E., \& Renz, M. (2016). Fuel and chemicals from wet lignocellulosic biomass waste streams by hydrothermal carbonization. Green Chem., 18(4), 1051-1060.

http://xlink.rsc.org/?DOI=C5GC02296G

Chen, Q., Liu, M., \& Xia, W. (2009). Study on Coal Plasma Ignition and Combustion in a Primary Combustor. In 2009 Asia-Pacific Power and Energy Engineering Conference (pp.1-5).

https://doi.org/10.1109/APPEEC.2009.4918809

Gai, C., Guo, Y., Liu, T., Peng, N., \& Liu, Z. (2016). Hydrogen-rich gas production by steam gasification of hydrochar derived from sewage sludge. International Journal of Hydrogen Energy, 41(5), 3363-3372. https://doi.org/10.1016/j.ijhydene.2015.12.188

Gorokhovski, M. A., Jankoski, Z., Lockwood, F. C., Karpenko, E. I., Messerle, V. E., \& Ustimenko, A. B. (2007). Enhancement of pulverized coal combustion by plasma technology. Combustion Science. Retrieved from http://www.tandfonline.com/doi/abs/10.1080/0010220070 1386115
Howard, J. B., \& Essenhigh, R. H. (1967). Mechanism of solidpartical combustion with simultaneous gas-phase volatiles combustion. Symposium (International) on Combustion, 11(1),-399-408.

https://doi.org/10.1016/S0082-0784(67)80164-4

Lemaire, R., Menage, D., Menanteau, S., \& Harion, J. L. (2014). Experimental study and kinetic modeling of pulverized coal devolatilization under air and oxycombustion conditions at a high heating rate. Fuel Processing Technology, 128, 183-190.

https://doi.org/10.1016/j.fuproc.2014.07.020

Matveev, I. B., Ardelyan, N. V, Bychkov, V. L., Bychkov, D. V, \& Kosmachevskii, K. V. (2013). Plasma Assisted Combustion, Gasification and Pollution Control. Int. Plasma Technol. Center (Vol. 1). Retrieved from plasmacombustion.org/imgs/book_advertising.pdf

Messerle, V. E., Karpenko, E. I., Ustimenko, A. B., \& Lavrichshev, O. A. (2013). Plasma preparation of coal to combustion in power boilers. Fuel Processing Technology, 107, 93-98. https://doi.org/10.1016/j.fuproc.2012.07.001

Messerle, V. E., Ustimenko, A. B., Askarova, A. S., \& Nagibin, A. O. (2010). Pulverized coal torch combustion in a furnace with plasma-coal system. Thermophysics and Aeromechanics, 17(3), 435-444.

https://doi.org/10.1134/S0869864310030145

Pacheco, J., Soria, G., Pacheco, M., Valdivia, R., Ramos, F., Frías, H., ... Hidalgo, M. (2014). Greenhouse gas treatment and $\mathrm{H} 2$ production, by warm plasma reforming. International Journal of Hydrogen Energy, 37(8), 10976. http://www.sciencedirect.com/science/article/pii/S036031 9915021928

Serbin, S. I., \& Matveev, I. B. (2010). Theoretical investigations of the working processes in a plasma coal gasification system. IEEE Transactions on Plasma Science, 38(12 PART 1), 3300-3305. https://doi.org/10.1109/TPS.2010.2086495

Sijer, M., Belosevic, S., \& Stefanovi, P. (2005). Modeling of Pulverized Coal Combustion, 57-72. Retrieved from http://www.doiserbia.nb.rs/img/doi/03549836/2005/035498360502057S.pdf

Singleton, D. R., Kuthi, A., Sanders, J. M., Gundersen, M. A., Simone, A., \& Pendleton, S. J. (2011). Low energy compact power modulators for transient plasma ignition. IEEE Transactions on Dielectrics and Electrical Insulation, 18(4),1084-1090. https://doi.org/10.1109/TDEI.2011.5976099

Smoot, L. D., \& Smith, P. J. (2013). Coal combustion and gasification (Springer S). Retrieved from https://books.google.es 
Sugimoto, M., Maruta, K., Takeda, K., Solonenko, O. P., Sakashita, M., \& Nakamura, M. (2002). Stabilization of pulverized coal combustion by plasma assist. Thin Solid Films, 407(1-2), 186-191. https://doi.org/10.1016/S00406090(02)00035-4

Therssen, E., Gourichon, L., \& Delfosse, L. (1995). Devolatilization of coal particles in a flat flameexperimental and modeling study. Combustion and Flame, 103(1-2), 115-128. https://doi.org/10.1016/00102180(95)00092-K

Timothy, L. D., Sarofim, A. F., \& Béer, J. M. (1982). Characteristics of single particle coal combustion. Symposium (International) on Combustion, 19 (1), 1123-1130.

https://doi.org/https:/doi.org/10.1016/S00820784(82)802889

Tomeczek, J., \& Kowol, J. (1991). Temperature field within a devolatilizing coal particle. The Canadian Journal of Chemical Engineering, 69(1), 286-293.

https://doi.org/10.1002/cjce.5450690135
Yan, B., Cheng, Y., Jin, Y., \& Guo, C. Y. (2012). Analysis of particle heating and devolatilization during rapid coal pyrolysis in a thermal plasma reactor. Fuel Processing Technology, 100(August), 1-10.

https://doi.org/10.1016/j.fuproc.2012.02.009

Yan, B. H., Cao, C. X., Cheng, Y., Jin, Y., \& Cheng, Y. (2014). Experimental investigation on coal devolatilization at high temperatures with different heating rates. Fuel, 117 (PARTB), 1215-1222. https://doi.org/10.1016/j.fuel.2013.08.016

Yu, J., Lucas, J. A., \& Wall, T. F. (2007). Formation of the structure of chars during devolatilization of pulverized coal and its thermoproperties: A review. Progress in Energy and Combustion Science, 33(2), 135-170. https://doi.org/10.1016/j.pecs.2006.07.003

Zhao, F., Li, S., Ren, Y., Yao, Q., \& Yuan, Y. (2016). Investigation of mechanisms in plasma-assisted ignition of dispersed coal particle streams. Fuel, 186, 518-524. https://doi.org/10.1016/j.fuel.2016.08.078 